\title{
Reactive oxygen species and their influence on stallion semen fertility - a review
}

\author{
Roland Pagl', Jörg Aurich' and Christine Aurich² \\ Clinic for Obstetrics, Gynaecology and Andrology ${ }^{1}$, Centre for Artificial Insemination and Embryo Transfer², Department of Animal Breeding and Reproduction \\ University of Veterinary Sciences, Vienna, Austria
}

\begin{abstract}
Summary
Losses in motility and fertilizing ability of stored semen can at least in part be attributed to lipid peroxidation of the sperm plasma membrane. Physiologically, mitochondrial respiration is the main source of reactive oxygen species (ROS). In processed semen, ROS originate from contaminating leucocytes and from spermatozoa with residual cytoplasm. In addition, normal spermatozoa produce ROS as a result of their flagellar activity. At low concentrations, ROS have positive biological effects and regulate physiological sperm functions. Mammalian sperm cell membranes have a specific lipid composition with a high content of polyunsaturated fatty acids, making them particularly susceptible to damage by ROS. Peroxidation increases membrane permeability and decreases metabolic activity of sperm cells. To control the effects of ROS, semen contains antioxidants. Enzymatic antioxidants are glutathione peroxidase, superoxide dismutase and catalase. Antioxidants have been substituted in semen through the diet or by adding antioxidants to semen extender. However, as the loss of sperm motility during cooled-storage is not only an effect of plasma membrane dysfunction but also of mitochondrial membrane dysfunction, addition of antioxidants to semen during cooled-storage may have only limited effects.
\end{abstract}

Keywords: reproduction, stallion, cooled semen, peroxidation

\section{Einfluss freier Sauerstoffradikale auf die Fertilität von Hengstsamen - eine Übersicht}

Motilitätsverluste und eine reduzierte Befruchtungsfähigkeit von gekühlt gelagertem Samen sind unter anderem auf eine vermehrte Peroxidation von Lipiden in der Spermienmembran zurückzuführen. Die mitochondriale Atmungskette ist unter physiologischen Bedingungen die Hauptquelle für Sauerstoffradikale (reactive oxygen species, ROS). ROS in aufbereitetem, gelagerten Samen stammen vor allem von kontaminierenden Leucozyten und von Spermien mit Zytoplasmatropfen. Normale Spermien produzieren ROS infolge ihrer Bewegungsaktivität. In geringen Konzentrationen haben ROS positive biologische Effekte und sind an der Regulation physiologischer Spermienfunktionen beteiligt. Spermien weisen eine spezifische Lipidzusammensetzung mit einem hohen Gehalt an mehrfach ungesättigten Fettsäuren auf. Dies macht die Spermienmembran besonders empfindlich für ROS-induzierte Peroxidationsvorgänge. Peroxidation erhöht die Membranpermeabilität und reduziert Stoffwechselvorgänge in den Spermien. Einer Schädigung der Spermien durch ROS wirken verschiedene Antioxidantien im Samen entgegen (u.a. Glutathionperoxidase, Superoxiddismutase und Katalase). Experimentell ist versucht worden, die antioxidative Kapazität im Samen durch Zusatz von Antioxidantien zum Samenverdünner sowie durch Fütterung von Antioxidantien zu erhöhen. Da Verluste der Spermienqualität während der gekühlten Lagerung nicht nur auf Schädigung der Spermienmembran, sondern auch auf Schädigung mitochondrialer Membranen zurückzuführen ist, hat der Zusatz von Antioxidantien zum Samen während der gekühlten Lagerung jedoch nur begrenzt positive Effekte.

Schlüsselwörter: Reproduktion, Hengst, Samenkonservierung, Peroxidation

\section{Introduction}

The use of cooled semen is a routine practice in modern horse reproduction. The widespread use of Al with cooled transported semen has accelerated genetic progress by making selected stallions available outside the region where the stallion is located. When semen transport from the collection centre to the place where the mare is to be inseminated can be organized within 24 hours, cooled semen is preferred to frozen semen because of its better fertilizing capacity. Furthermore, Al with semen from stallions of controlled genital health status has markedly reduced the risk of sexual transmissible diseases for the mare.

Despite its obvious advantages, Al does not always lead to satisfying pregnancy results. Reasons range from fertility pro- blems in the mare, low semen quality and inadequate treatment of the ejaculate to wrong timing of insemination. However, even if these apparent critical points are avoided, semen from certain stallions rapidly looses motility and viability during cooled storage. Although overall losses in motility and fertilizing ability of stored semen can at least in part be attributed to lipid peroxidation of the sperm plasma membrane (Aitken 1994, Storey 1997), the reasons why individual stallions have a low fertility when used via cooled or frozen-thawed semen are currently not well understood (Brinsko et al. 2000, Battelier et al. 2001). It has been suggested that cholesterol content of the sperm plasma membrane may affect suitability of semen from individual males for cooled-storage (Cross 1998, for review see Aurich 2005). In men, a relation between reduced fertility and production of reactive oxygen species (ROS) in 
semen has been demonstrated. Less information is available on ROS production and male fertility in animals.

\section{Generation of reactive oxygen species}

Reactive oxygen species are short-lived reactive chemical intermediates containing one or more electrons with unpaired spin (Sanocka and Kurpisz 2004). As free radicals they are highly reactive and oxidize lipids, amino acids and carbohydrates and can cause DNA damage. Therefore, ROS have been suggested as an aetiological factor in a variety of diseases (Rowley et al. 1984, Andorn et al. 1990, White et al. 1994).

Generation of ROS occurs during normal cell metabolism. Physiologically, mitochondrial respiration is the main source of superoxide anion radicals. During reduction of oxygen to water by cytochrome $\mathrm{C}$ oxidase, ROS can leak into the cell (Sanocka and Kurpisz 2004). As shown in humans, spermatozoa generate superoxide anions (Aitken and Clarkson 1987, Alvarez et al. 1987). Because of a low reactivity and short half-life this molecule is not particularly harmful and dismutates spontaneously or under the influence of intracellular superoxide dismutase to hydrogen peroxide. However, by reacting with other molecules, it can transform these targets into more toxic radicals (Alvarez and Storey 1984, Halliwell and Gutteridge 1989). Hydrogen peroxide is relatively stable, has a higher oxidant potential than superoxide anion and permeates biological membranes (DeLamirande et al. 1997). Small amounts of iron, which is nearly ubiquituous in biological fluids, catalyses the formation of hydroxyl radicals from $\mathrm{H}_{2} \mathrm{O}_{2}$. This ROS has toxic effects on many cell components, but a short half-life.

In processed semen, ROS originate mainly from contaminating leucocytes (Aitken et al. 1994, DeLamirande and Gagnon 1994, Plante et al. 1994, Whittington and Ford 1999) and from spermatozoa with excess residual cytoplasm (Aitken and Baker 2004, Brouwers et al. 2005). In humans, granulocytes in semen originate from the epididymis, prostate (Simbini et al. 1998) but also the seminal vesicles (Gonzales et al. 1992).

Spermatozoa with residual cytoplasm, indicating insufficient maturation, produce significantly more ROS than normal spermatozoa (Gomez et al. 1996, Aitken and Baker 2004, Brouwers et al. 2005). Also spermatozoa with other morphological deformities such as tail defects have an increased ROS production (Aziz et al. 2004). Spermatozoa in different stages of maturation produce different amounts of ROS (Gil-Guzman et al. 2001). This may be related to a higher activity of enzymes such as glucose-6-phosphate-dehydrogenase involved in ROS production (Gomez et al. 1996, Aitken et al. 1997, Esfandiari et al. 2003, Aziz et al. 2004). Sertoli cell function may be affected by ROS producing leucocytes, leading to disturbances in spermatogenesis and deformed spermatozoa (Henkel et al. 2005). However, it remains unclear to what degree leucocytes exert their effects on spermatozoa during spermatogenesis, epidydimal maturation or after ejaculation.

In addition, normal spermatozoa produce ROS as a result of their flagellar activity (Gavella and Lipovac 1992). Ram spermatozoa specifically produce ROS using an amino acid oxidase that generates hydrogen peroxide and thus suppresses sperm motility (Upreti et al. 1992). Centrifugation of semen and removal of $90 \%$ of seminal plasma has beneficial effects on sperm viability during cooled storage (Pickett et al. 1975) but centrifugation does also increase the amount of ROS in semen (DeJager et al. 1996, Parinaud et al. 1997).

\section{Biological effects of reactive oxygen species on sperma- tozoa}

At low concentrations, ROS have positive biological effects and act selectively on prostanoid metabolism, gene regulation, cellular growth, signal transduction pathways and participate in the regulation of vasotonus and antimicrobial defense. Low ROS levels also regulate physiological sperm functions (DeLamirande et al. 1997, Sanocka and Kurpisz 2004). Small amounts of free radicals in human semen stimulate sperm capacitation, hyperactivation, acrosome reaction and sperm oocyte fusion (Saran and Bors 1989, DeLamirande and Gagnon 1993a, Griveau and LeLannou 1997, Delamirande et al. 1998). An increase in extracellular superoxide anions is essential for capacitation (DeLamirande

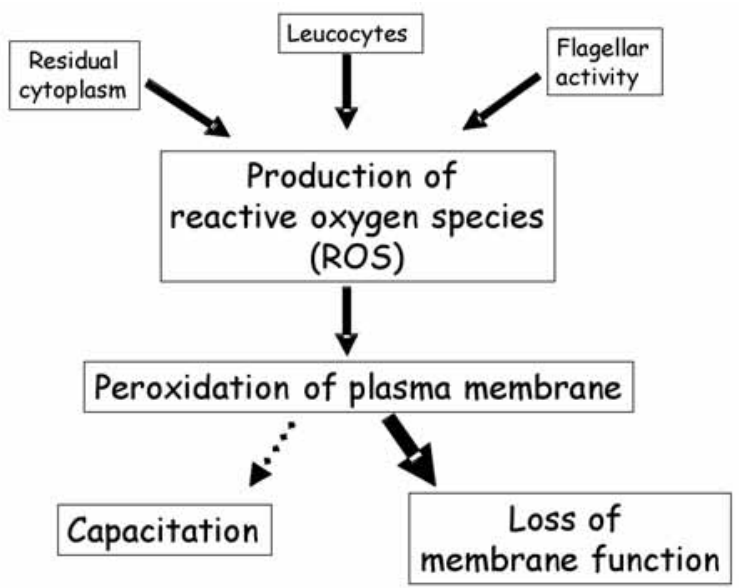

Fig 1 Source and effects of reactive oxygen species in semen Herkunft und Wirkung freier Saverstoffradikale im Samen

and Gagnon 1995) and low concentrations of hydrogen peroxide stimulate capacitation and hyperactivation (Bauskin et al. 1991, Griveau et al. 1994). Reactive oxygen species also play a role in the acrosome reaction and in zona pellucida binding (Aitken et al. 1989 and 1995). Conversely, the block of ROS production with catalase inhibits hyperactivation and acrosome reaction (Griveau et al. 1994). All these processes are redox-regulated and mild oxidative conditions are needed for spermatozoa to reach their full fertilization capacity. Because the effects of ROS added to semen (e.g. induction of the acrosome reaction) last longer than the actual presence of ROS in the sample, it has been suggested that ROS only initialize a cascade leading finally to fertilization (Bize et al. 1991, DeLamirande and Gagnon 1993a and b). Some authors suggest that a specific enzyme in the sperm membrane is activated during capacitation (DeLamirande and Gagnon 1993b, Aitken et al. 1995, DeLamirande and Gagnon 1995). The acrosome reaction involves tyrosine phosphorylation of specific proteins ( $\mathrm{Naz}$ et al. 1991, Tesarik et al. 1993) and tyrosine kinases and phosphatases are redox regulated (Bauskin et al. 1991, Hecht and Zick 1992) 


\section{Negative effects of reactive oxygen species on sperma- tozoa}

Spermatozoa are highly specialised cells for the transport of paternal DNA to the oozyte. Mammalian sperm cell membranes have a specific lipid composition with a high content of polyunsaturated fatty acids, plasmalogens (ether-linked lipids) and sphingomyelins. Like most biological membranes, they have an asymmetrical arrangement of lipids within the lipid bilayer. Lipid composition of the sperm plasma membrane is different from somatic cells with an increased content of phospholipids, sterols, satured and polyunsaturated fatty acids. Amongst the sterols, the efflux of cholesterol from the sperm plasma membrane plays an important role for capacitation (Cross 1998). Composition of the plasma membrane changes from epididymal maturation to penetration of the oozyte, with plasmalogenes becoming the major phospholipids (Aveldano et al. 1992).

Conditions in the female genital tract are primarily anaerobic, reducing the potential damage to spermatozoa by ROS (Foote et al. 2002). Their special structure and high amount of polyunsaturated fatty acids (PUFA) makes mammalian spermatozoa in processed semen particularly susceptible to damage by ROS (Kodama et al. 1996). Peroxidation of PUFA in sperm cell membranes is an autocatalytic, self propagating reaction, resulting in the loss of membrane functionality and integrity. Peroxidation can be divided into the steps of initiation, propagation and termination. Initiation of peroxidation is the abstraction of a hydrogen atom from an unsaturated fatty acid. Propagation is defined as formation of a lipid alkyl radical followed by its rapid reaction with oxygen to a lipid peroxyl radical. Peroxyl radicals ignite a chain reaction in which the intermediate product lipid hydroperoxide is formed. In the presence of iron ions lipid hydroperoxides desintegrate into alkoxy radicals or peroxyl radicals. At termination of the chain reaction all oxygen and hydrogen species are used off and the peroxyl radical reacts to a stable product.

Extrinsic ROS from leucocytes as well as intrinsic ROS from spermatozoa also induce DNA fragmentation (Lopes et al. 1998, Irvine et al. 2000). The source of ROS clearly influences their effects. Intrinsic ROS production is highly correlated with DNA fragmentation. From the extrinsically produced ROS only $\mathrm{H}_{2} \mathrm{O}_{2}$ but not superoxid and hydroxyl radicals are membrane permeable. Thus, in biological systems, only $\mathrm{H}_{2} \mathrm{O}_{2}$ can damage DNA while other extrinsic $\mathrm{ROS}$ will cause mainly lipid peroxidation of cell membranes (Henkel et al. 2005). Leucocyte-derived extrinsic ROS production is positively correlated with the sperm cells own, intrinsic ROS production, indicating that damaged spermatozoa produce more ROS than intact ones (Saleh et al. 2002).

In humans, it has been demonstrated by measuring mitochondrial membrane potential (MMP) that ROS also damage mitochondria. Men with abnormal semen parameters have decreased MMPs and high ROS concentrations in semen. Damaged mitochondria may also play a role in apoptosis. Compared with normal men, infertile semen donors had significantly higher levels of ROS, cytochrome $\mathrm{C}$ and caspase 3 and 9. Cytochrome $C$ is a marker for mitochondrial integrity because it leaks from damaged mitochondria into seminal plasma. Caspases are proteases that promote apoptosis.
Release of these proteins from mitochondria due to oxidative stress is likely to accelerate apoptosis (Wang et al. 2003a and b).

Peroxidation increases membrane permeability and thus decreases metabolic activity of sperm cells due to permeation of enzymes, substrates nucleotide cofactors and ATP (Storey 1997). Therefore, loss of motility is not only related to lipid peroxidation of the plasma membrane, but also to a decrease in energy supply by the mitochondria due to ATP depletion (DeLamirande and Gagnon 1992, Ruiz-Pesini et al. 1998).

\section{Antioxidative defence systems in semen}

To control the negative effects of ROS, mammalian ejaculates contain intra and extracellular antioxidants of enzymatic and non enzymatic origin. Enzymatic antioxidants are glutathione peroxidase (GSH-Px), superoxide dismutase (SOD) and catalase (CAT). SOD specifically scavenges superoxide radicals and converts them to hydrogen peroxide and oxygen which in turn are broken down into water by CAT and GSHPx. Superoxide radicals, supposed to be the primary species generated by spermatozoa, are neutralized by SOD to $\mathrm{H}_{2} \mathrm{O}_{2}$, which also damages spermatozoa and is neutralized by CAT and GSH-Px. Non enzymatic, low molecular weight antioxidants are $\alpha$-tocopherol, $\beta$-carotene, ascorbate, urate, transition-metal chelators, transferrin, lactoferrin and caeruloplasmin (Sanocka and Kurpisz 2004).

All glutathione peroxidases reduce hydrogen peroxide and alkyl hydroperoxides at the expense of glutathione with different specificity. Amongst about 30 mammalian selenoproteins the most known are cytosolic GSH-Px (cGSH-Px), phospholipids hydroperoxide GSH-Px (PHGSH-Px), plasma GSH-Px (pGSH-Px) and gastrointestinal GSH-Px (GIGSH-Px). The enzymes cGSH-Px, pGSH-Px and GIGSH-Px are homotetramers and PHGSH-Px is a monomer with a molecular size smaller than the subunits of the other glutathione peroxidases (Brigelius-Flohe 1999). All seleno-dependent peroxidases require selenium for their biosynthesis and activity but respond differently to selenium deficiency. The most stable isoform is GIGSH-Px followed by PHGSH-Px and pGSH-Px and cGSH-Px. The extracellular isoenzyme pGSH-Px regulates hydroperoxide turnover in blood plasma but also in milk and extracellular fluid of the intestine, lung and in amniotic fluid. Cytosolic GSH-Px is thought to counteract hydroperoxide-modulate apoptosis (Kayanoki et al. 1996) or eicosanoid metabolism (Weitzel and Wendel 1993) within cells. Its expression in the epithelium of the gastrointestinal tract makes GIGSH-Px a major antioxidant of the intestinal epithelium (Esworthy et al. 1998) and a defense against ingested lipid hydroperoxides (Chu et al. 1993).

The enzyme PHGSH-Px is the major peroxidase in the testes (Brigelius-Flohe 1999). It is distributed between the cytosol and subcellular organelles and exists in high amounts in mitochondrial membranes and nuclei (Godeas et al. 1994 and 1996). The isoform specifically reduces phospholipid hydroperoxides into their corresponding alcohols thus interrupting the cascade of radical formation (Ursini et al. 1982). PHGSH-Px is also involved in sperm maturation and differentiation. By oxidizing $\mathrm{SH}$ groups of protamines from epididymal 
sperm in the presence of hydroperoxides, PHGSH-Px participates in the condensation of chromatin (Godeas et al. 1997). A positive correlation exists between seminal plasma selenium and sperm density, sperm number, motility and viability in humans ( $X_{U}$ et al. 2003).

Superoxide dismutases are metalloproteins, divided into 3 groups depending on the ion in their active center. SOD containing $\mathrm{Cu} / \mathrm{Zn}$ is found mainly in the cytosol, Mn SOD is found in mitochondria and Fe SOD exists mainly in procaryota. An extracellular form of Cu/Zn SOD was detected in extracellular matrix and fluids of eucaryota as well. Superoxide dismutase has a high affinity for heparin. It dismutates the superoxide radical into peroxide and molecular oxygen. Hydrogen peroxide, which is able to cross cell membranes, must be removed by either catalase or GSH-Px. In rat testis, cytosolic, mitochondrial as well as extracellular SOD were detected (Bauche et al. 1993). In humans, nearly all SOD activity in sperm is from the cytosolic isoenzyme (McCord and Fridovich 1969).

Semen catalase has been studied in humans (Jeulin et al. 1989) but also stallions (Ball et al. 2000, Koskinen et al. 2002). CAT is responsible for dismutation of $\mathrm{H}_{2} \mathrm{O}_{2}$ to $\mathrm{O}_{2}$ and $\mathrm{H}_{2} \mathrm{O}$. Activity of CAT has been analysed in testes, accessory sexual glands and cauda epididymal fluid of stallions (Ball et al. 2000). The major source are prostatic secretions and at least part of CAT activity in spermatozoa represents adsorbed molecules from prostatic fluid. Koskinen et al. (2002) determined CAT activity in different fractions of stallion ejaculates and found the lowest activity in pre-ejaculatory fluid.

\section{Addition of antioxidants to semen and semen extenders}

Antioxidants have been substituted in semen either through the diet or by adding antioxidants to semen extender before dilution and storage of semen. Oral intake of vitamin $C$ and $\mathrm{E}$ prevented $\mathrm{Pb}$-associated sperm $\mathrm{ROS}$ generation in $\mathrm{Pb}$ exposed rats, increased epididymal sperm motility and enhanced the capacity of spermatozoa to penetrate oocytes in vitro (Hsu et al. 1998). Oral treatment of asthenozoospermic men with vitamin $\mathrm{E}$ decreased lipid peroxidation in semen and improved sperm motility (Suleiman et al. 1996). In birds, where prolonged storage of spermatozoa occurs in specialised sites of the female genital tract, maintenance of the fertilizing ability of spermatozoa mainly seems to depend on the presence of efficient antioxidative systems (Brèque et al. 2003).

Also direct addition of antioxidants to semen before storage has protective effects on sperm function. Positive effects of added antioxidants, however, depend on the individual extender and antioxidant used. Addition of ascorbic acid to skim milk extender increases the percentage of membrane-intact spermatozoa (Aurich et al. 1997) while addition of pyruvate increased the percentage of motile spermatozoa (Bruemmer et al. 2002) during storage at $5^{\circ} \mathrm{C}$ and also fertility. Similar effects have been found in humans (Parinaud et al. 1997) and in bulls (Foote et al. 2002) after addition of different antioxidants to semen. GSH-Px added to ram semen had positive effects on sperm motility and acrosome integrity during cooled storage (Maxwell and Stojanov 1996). In humans, antioxidants like glutathione or $\mathrm{N}$-acetylcysteine have been suggested to protect against the damaging effects of leukocyte-derived ROS on sperm motility and may be of clinical value in assisted reproduction procedures (Baker et al. 1996). Griveau et al. (1994) investigated the effect of the addition of dithriothreitol, reduced glutathione (GSH), CAT and SOD to semen. Dithriothreitol and SOD increased hyperactivation and acrosome reaction while GSH improved the acrosome reaction, indicating a potential therapeutic use in men.

A positive effect of milk-based extenders alone, i.e. without added antioxidants, on the antioxidative activity in diluted stallion semen could be demonstrated recently (Kankofer et al. 2005). Activity of GSH-Px, SOD and CAT was increased after dilution of semen with a milk-based extender. The same effect was seen when seminal plasma alone, but not when spermatozoa separated from seminal plasma were diluted with semen extender. This suggests interactions between seminal plasma and extender resulting in an increase in antioxidative capacity. The protective effects of many routinely used semen extenders may be related at least in part to an increase in antioxidative capacity after dilution of semen.

However, as the loss of sperm motility during cooled-storage is not only an effect of plasma membrane dysfunction but also of mitochondrial membrane dysfunction (DeLamirande and Gagnon 1992, Ruiz-Pesini et al. 1998), addition of antioxidants to semen during cooled-storage may only have limited effects.

\section{Literature}

Aitken R. J. (1994): A free radical theory of male infertility. Reprod. Fertil. Dev. 6, 19-24

Aitken R. J. and Clarkson J. S. (1987): Cellular basis of defective sperm function and its association with the genesis of reactive oxygene species by human spermatozoa. J. Reprod. Fertil. 81, 459469

Aitken R. J. and Baker M. A. (2004): Oxidative stress and male reproductive biology. Reprod. Fertil. Dev. 16, 581-588

Aitken R. J., Clarkson J. S. and Fishell S. (1989): Generation of reactive oxygen species, lipid peroxidation and human sperm function. Biol. Reprod. 40, 183-197

Aitken R. J., West K. and Buckingham D. (1994): Leukocytic infiltration into the human ejaculate and its association with semen quality, oxidative stress, and sperm function. J. Androl. 15, 343-352

Aitken R. J., Paterson M., Fisher H., Buckingham D. W. and VanDuin M. (1995): Redox regulation of tyrosine phosphorylation in human spermatozoa and its role in the control of human sperm function. J. Cell. Sci. 180, 2017-2025

Aitken R. J., Fisher H. M., Fulton N., Gomez E., Knox W. and Lewis B. (1997): Reactive oxygen species generation by human spermatozoa is induced by exogenous NADPH and inhibited by the flavoprotein inhibitors diphenylene iodonium and quinacrine. Mol. Reprod. Dev. 47, 468-482

Alvarez J. G. and Storey B. T. (1984): Lipid peroxidation and the reactions of superoxide and hydrogene peroxid in mouse spermatozoa. Biol. Reprod. 30, 833-841

Alvarez J. G., Touchstone J. C., Blasco L. and Storey B. T. (1987): Spontaneous lipid peroxidation and production of hydrogen peroxide and superoxide in human spermatozoa: Superoxide dismutase as a major enzyme protectant against oxygene toxicity. J. Androl. 8, 338-348

Andorn A. C., Britton R. S. and Bacon B. R. (1990): Evidence that lipid peroxidation and total iron are increased in Alzheimer's brain. Neurobiol. Aging 11, 316-320 
Aurich C. (2005): Factors affecting the plasma membrane function of cooled-stored stallion spermatozoa. Anim. Reprod. Sci. 89, 65-75

Aurich J. E., Schönherr U., Hoppe H. and Aurich C. (1997): Effects of antioxidants on motility and membrane integrity of chilled-stored stallion semen. Theriogenology 48, 185-192

Aveldano M. I., Rotstein N. P. and Vermouth N. T. (1992): Lipid remodeling during epididymal maturation of rat spermatozoa. Enrichement in plasmenylcholines containing long-chain polyenoic fatty acids of the n-9series. Biochem. J. 283, 235-241

Aziz N., Saleh R. A., Sharma R. K., Lewis-Jones I., Esfandiari N. and Thomas A. J. (2004): Novel association between sperm reactive oxygen species production, sperm morphological defects and the sperm deformity index. Fertil. Steril. 81, 349-354

Baker H. W. G., Brindle J., Irvine D. S. and Aitken R. J. (1996): Protective effect of antioxidants on the impairment of sperm motility by activated polymorphonuclear leukocytes. Fertil. Steril. 65, 41 1-419

Ball B. A., Gravance C. G., Medina V. and Baumber J. (2000): Catalase activity in equine semen. Am. J. Vet. Res. 61, 1026-1030

Battelier F., Vidament M., Fauquant J., Duchamp G., Arnaud G., Yvon J. M. and Magistrini M. (2001): Advances in cooled semen technology. Anim. Reprod. Sci. 68, 181-190

Bauche F., Fouchard M. H. and Jegou B. (1993): Antioxidant system in the rat testicular cells. FEBS Lett. 349, 392-396

Bauskin A. R., Alkalai I. and Ben-Neriah Y. (1991): Redox regulation of tyrosine kinase in the endoplasmic reticulum. Cell 56, 685-696

Bize I., Santander G., Cabello P., Driscoll D. and Sharpe C. (1991): Hydrogene peroxide is involved in hamster sperm capacitation in vitro. Biol. Reprod. 44, 398-403

Brèque C., Surai P. and Brillard J. P. (2003): Roles of antioxidants on prolonged storage of avian spermatozoa in vivo and in vitro. Mol. Reprod. Dev. 66, 314-323

Brigelius-Flohe R. (1999): Tissue specific functions of individual glutathione peroxidases. Free Radical Biol. Med. 27, 951-965

Brinsko S. P., Cockett E. C. and Squires E. L. (2000): Effect of centrifugation and partial removal of seminal plasma on equine spermatozoal motility after cooling and storage. Theriogenology 54, $129-136$

Brouwers J. F., Silva P. F. N. and Gadella B. M. (2005): New assays for detection and localization of endogenous lipid peroxidation products in living boar sperm after BTS dilution or after freeze-thawing. Theriogenology 63, 458-469

Bruemmer J. E., Coy R. C., Squires E. L. and Graham J. K. (2002): Effect of pyruvate on the function of stallion spermatozoa stored for up to 48 hours. J. Anim. Sci. 80, 12-28

Chu F. F., Doroshow J. H. and Esworthy R. S. (1993): Expression, characterization and tissue distribution of a new cellular selenium dependent glutathione peroxidase, GSH-Px-GI. J. Biol. Chem. 268, 2571-2576

Cross N. L. (1998): Role of cholesterol in sperm capacitation. Biol. Reprod. 95, 7-11

DeJager C., Bornman M. S. and Aneck-Hahn N. H. (1996): Effect of rotation on the generation of reactive oxygen species in human semen. Andrologia 28, 291-293

DeLamirande E. and Gangnon C. (1992): Reactive oxygen species and human spermatozoa. II. Depletion of adenosine triphosphate plays an important role in inhibition of sperm motility. J. Androl. 13, 379-386

DeLamirande E. and Gagnon C. (1995): Capacitation-associated production of superoxide anion by human spermatozoa. Free Radical Biol. Med. 18, 487-495

DeLamirande E. and Gagnon C. (1993a): A positive role for the superoxide anion in triggering hyperactivation and capacitation of human spermatozoa. Int. J. Androl. 16, 21-25

DeLamirande E. and Gagnon C. (1993b): Human Sperm hyperactivation and capacitation as parts of an oxidative process. Free Radical Biol. Med. 14, 157-163

DeLamirande E. and Gagnon C. (1994): Reactive oxygen species (ROS) and reproduction. Adv. Exp. Med. Biol. 366, 185-197

DeLamirande E. and Gagnon C. (1995): Capacitation-associated production of superoxide anion in human spermatozoa. J. Androl. Suppl. 1, P54
DeLamirande E., Jiang H., Zini A., Kodama H. and Gagnon C. (1997): Reactive oxygen species and sperm physiology. Rev. Reprod. 2, 48-54

DeLamirande E., Harakat A. and Gagnon C. (1998): Human sperm capacitation induced by biological fluids and progesterone, but not by NADH or NADPH, is associated with the production of superoxide anion. J. Androl. 19, 215-225

Esfandiari N., Sharma R. K., Saleh R. A., Thomas A. J. and Agarwal A. (2003): Utility of the nitroblue tetrazolium reduction test for assessment of reactive oxygen species production by seminal leukocytes and spermatozoa. J. Androl. 24, 862-870

Esworthy R. S., Swiderek K. M., Ho Y. S. and Chu F. F. (1998): Selenium-dependent glutathione peroxidase-GI is a major glutathione peroxidase activity in the mucosal epithelium of rodent intestine. Biochim. Biophys. Acta. 1381, 213-226

Foote R. H., Brockett C. C. and Kaproth M. T. (2002): Motility and fertility of bull sperm in whole milk extender containing antioxidants. Anim. Reprod. Sci. 71, 13-23

Gavella M. and Lipovac V. (1992): NADH-dependent oxidoreductase (diaphorase) activity and isozyme pattern of sperm in infertile men. Arch. Androl. 28, 135-141

Gil-Guzman E., Ollero M., Lopez M. C., Sharma R. K., Alvarez J. G. and Thomas A. J. (2001): Differential production of reactive oxygen species by subsets of human spermatozoa at different stages of maturation. Hum. Reprod. 16, 1922-1930

Godeas C., Sandri G. and Panfili E. (1994): Distribution of phospholipids hydroperoxide glutathione peroxidase (PHGPx) in rat testis mitochondria. Biochem. Biophys. Acta. 1191, 147-150

Godeas C., Tramer F., Micali F., Roveri A., Maiorino M., Nisii C., Sandri G. and Panfili E. (1996): Phospholipid hydroperoxide glutathione peroxidase (PHGPx) in rat testis nuclei is bound to chromatin. Biochem. Mol. Med. 59, 118-124

Godeas C., Tramer F., Micali F., Soranzo M. R., Sandri G. and Panfili E. (1997): Distribution and possible novel role of phospholipids hydroperoxide glutathione peroxidase in rat epididymal spermatozoa. Biol. Reprod. 57, 1502-1508

Gomez E., Buckingham D. W., Brindle J., Lanzafame F., Irvine D. S. and Aitken R. J. (1996): Development of an image analysis system to monitor the retention of residual cytoplasma by human spermatozoa: Correlation with biochemical markers of the cytoplasmic space, oxidative stress and sperm function. J. Androl. 17, 276287

Gonzales G. F., Kortebani G. and Mazzoli A. B. (1992): Leukocytospermia and function of the seminal vesicles on seminal quality. Fertil. Steril. 57, 1058-1065

Griveau J. F. and LeLannou D. (1997): Reactive oxygen species and human spermatozoa: Physiologiy and pathology. Intern. J. Androl. $20,61-69$

Griveau J. F., Renard P. and LeLannou D. (1994): An invitro promoting role for hydrogen peroxide in human sperm capacitation. Intern. J. Androl. 17, 300-307

Halliwell B. and Gutteridge J. M. C. (1989): Free Radicals in Biology and Medicine (2nd edn) Clarendon Press, Oxford

Hecht D. and Zick Y. (1992): Selective inhibition of proteine tyrosine phosphatase activities by $\mathrm{H}_{2} \mathrm{O}_{2}$ and vanadate in vitro. Biochem. Biophys. Res. Commun. 188, 773-779

Henkel R., Kierspel E., Stalf T., Mehnert C., Menkveld R., Tinneberg H. R., Schill W. B. and Kruger T. F. (2005). Effect of reactive oxygen species produced by spermatozoa and leukocytes on sperm functions in non-leukocytospermic patients. Fertil. Steril. 83, 635642

Hsu P., Liu M., Hsu C., Chen L. and Guo Y. L. (1998). Effects of vitamine $E$ and/or $C$ on reactive oxygen species-related lead toxicity in the rat sperm. Toxicology 1128, 169-179

Irvine D. S., Twigg J. P., Gordon E. L., Fulton N., Milne P. A. and Aitken R. J. (2000): DNA integrity in human spermatozoa: Relationships with semen quality. J. Androl. 21, 33-44

Jeulin C., Soufir J. C., Weber P., Laval-Martin D. and Calvayrac R. (1989): Catalase activity in human spermatozoa and seminal plasma. Gamete Res. 24, 185-196 
Kankofer M., Kolm G., Aurich J. E. and Aurich C. (2005): Activity of glutathione peroxidase, superoxide dismutase and catalase and lipid peroxidation intensity in stallion semen during storage at $5^{\circ} \mathrm{C}$. Theriogenology 63, 1354-1365

Kayanoki Y., Fujiii J., Islam K.N., Suzuki K., Kawata S., Matsuzawa Y. and Taniguchi N. (1996): The protective role of glutathione peroxidase in apoptosis induced by reactive oxygen species. J. Biochem. 119, 817-822

Kodama H., Kurbayashi Y. and Gagnon C. (1996): Effect of sperm lipid peroxidation on fertilization. J. Androl. 17, 151-157

Koskinen E., Karlsson M., Reilas T., Sankari S., Esala A. L. and Katila T. (2002): Catalase activity and total protein in fractionated stallion seminal plasma. Theriogenology 58, 337-340

Lopes S., Jurisicova A., Sung J. G. and Casper R. F. (1998): Reactive oxygen species: Potential cause for DNA fragmentation in human spermatozoa. Hum. Reprod. 13, 896-900

Mahadevan M. M., Miller M. M. and Moutos D. M. (1997): Absence of glucose decreases human fertilisation and sperm movement characteristics in vitro. Hum. Reprod. 12, 119-123

Maxwell W. M. C. and Stojanov T. (1996): Liquid storage of ram semen in the absence or presence of some antioxidants. Reprod. Fertil. Dev. 8, 1013-1020

McCord J. M. and Fridovich I. (1969): Superoxide dismutase: an enzymatic function for erythrocuprein (hemocuprein). J. Biol. Chem. 244, 6049-6055

Naz R. K., Ahmed K. and Kumar R. (1991): Role of membrane tyrosine proteins in human spermatozoal function. J. Cell. Sci. 99, 157-165

Parinaud J., LeLannou D., Vieitez G., Griveau J. F., Milhet P. and Richoilley G. (1997): Enhancement of motility by treating spermatozoa with an antioxidant solution $\left(\right.$ Spermfit ${ }^{\circledR}$ ) following ejaculation. Hum Reprod 12, 2434-2436

Pickett B. W. Sullivan J. J., Buyers W. W., Pace M. M. and Remmenga E. E. (1975): Effect of centrifugation and seminal plasma on motility and fertility of stallion and bull spermatozoa. Fertil. Steril. 26, 167-174

Plante M., DeLamirande E. and Gagnon C. (1994): Reactive oxygene species released by activated neutrophils, but not deficient spermatozoa, are sufficient to affect normal sperm motility. Fertil. Steril. 62, 387-393

Rowley A., Gutteridge J. M. C., Blake D. R., Farr M. and Halliwell B. (1984): Lipid peroxidation in rheumatoid arthritis: Thiobarbituric acid reactive material and catalytic iron salts in synovial fluid from rheumatoid patients. Clin. Sci. 66, 691-695

Ruiz-Pesini E., Diez C., Lapena A. C., Perez-Martos A., Montoya J., Alvarez E., Arena J. and Lopez-Perez M. J. (1998): Correlation of sperm motility with mitochondrial enzymatic activity. Clin. Chem. $44,1616-1620$

Saleh R. A., Agarwal A., Kandirali E., Sharma R. K., Thomas A. J. Jr, Nada E. A., Evenson P. D. and Alvarez J. G. (2002): Leukocytospermia is associated with increased reactive oxygen species production by human spermatozoa. Fertil. Steril. 78, 12151224

Sanocka D. and Kurpisz M. (2004): Reactive oxygene species and sperm cells. Reprod. Biol. Endocrinol. 2, 12

Saran M. and Bors W. (1989): Oxygen radicals acting as chemical messengers: A hypothesis. Free Radical Res. Commun. 7, $213-$ 220
Simbini T., Umapathy E., Jacobus E., Tendaupenyu G. and Mbizvo M. T. (1998): Study on the origin of seminal leucocytes using split ejaculate technique and the effect of leucocytospermia on sperm characteristics. Urol. Intern. 61, 95-100

Storey B. T. (1997): Biochemistry of the induction and prevention of lipoperoxidative damage in human spermatozoa. Mol. Hum. Reprod. 3, 203-213

Suleiman S. A., Ali M. E., Zaki Z. M. S., El-Malik E. M. A. and Nasr M. A. (1996). Lipid peroxidation and human sperm motility: Protective role of vitamin E. J. Androl. 17, 530-537

Tesarik J., Moos J. and Mendoza C. (1993): Stimulation of proteine tyrosine phosphorylation by a progesterone receptor on the surface of human sperm. Endocrinology 133, 328-335

Upreti G. C., Jensen K., Munday R., Duganzich D. M., Vishwanath R. and Smith J. F. (1992): Studies on aromatic amino acid oxidase activity in ram spermatozoa: Role of pyruvate as an antioxidant. Anim. Reprod. Sci. 51, 257-287

Ursini F., Maiorino M., Valente M., Ferri L. and Gregolin C. (1982): Purification from pig liver of a protein which protects liposomes and biomembranes from peroxidative degradation and exhibits glutathione peroxidase activity on phosphatidylcholine hydroperoxides. Biochem. Biophys. Acta 710, 197-211

Wang X., Sharma R. K., Gupta A., George V., Thomas A. J., Falcone T. and Agarwal A. (2003a): Alterarions in mitochondrial membrane potential and oxidative stress in infertile men: A prospective observational study. Fertil Steril 80, Suppl. 2, 844-850

Wang X., Sharma R. K., Sikka S. C., Thomas A. J., Falcone T. and Agarwal A. (2003b): Oxidative stress is associated with increased apoptsis leading to spermatozoa DNA damage in patients with male factor infertility. Fertil. Steril. 80, 531-535

Weitzel F. and Wendel A. (1993): Selenoenzymes regulate the activity of leukocyte 5-lipoxygenase via the peroxide tone. J. Biol. Chem. 268, 6288-6292

White C. R., Brock T. A., Chang L. Y., Crapo J., Briscoe P., Ku D., Bradley W. A., Gianturco S. H., Gore J., Freeman B. A. and Tarpey M. M. (1994): Superoxide and peroxynitrite in atherosclerosis. Proc. Nat. Acad. Sci. USA 91, 1044-1048

Whittington K. and Ford W. C. (1999): Relative contribution of leukocytes and of spermatozoa to rective oxygene species production in human sperm suspensions. Intern. J. Androl. 22, 229-235

Xu D. X., Shen H. M., Zhu Q. X., Chua .L, Wang Q. N., Chia S. E. and Ong C. N. (2003): The associations among semen quality, oxidative DNA damage in human spermatozoa and concentrations of cadmium, lead and selenium in seminal plasma. Mutation Res./Genet. Toxicol. Environ. Mutagen. 534, 155-163

Prof. Dr. Jörg Aurich

Clinic for Obstetrics, Gynaecology and Andrology

Department of Animal Breeding and Reproduction

University of Veterinary Sciences

Veterinaerplatz 1

1210 Vienna

Austria

joerg.aurich@vu-wien.ac.at 